\title{
Reliability Improvement of Offshore Structural Steel F690 Using Surface Crack Nondamaging Technology
}

\author{
Weon-Gu Lee ${ }^{\circledR 1}$, Kyoung-Hee $\mathrm{Gu}^{\oplus^{2}}$, Cheol-Su Kim $\circledast^{{ }^{3}}$ and Ki-Woo Nam ${ }^{22,4}$ \\ ${ }^{1}$ Princial Engineer, DS Mirae-tech Co., Ltd, Gyeongnam, Korea \\ ${ }^{2}$ Graduate Student, Department of Marine Convergence Design Engineering, Pukyong National University, Busan, Korea \\ ${ }^{3}$ Senior researcher, Eco-friendly Transport Systems Research Institute, Pukyong National University, Busan, Korea \\ ${ }^{4}$ Professor, Department. of Materials Science and Engineering, Pukyong National University, Busan, Korea
}

KEY WORDS: Nondamaging technology, Shot peening, Compressive residual stress, Offshore structural steel, Reliability

ABSTRACT: Microcracks can rapidly grow and develop in high-strength steels used in offshore structures. It is important to render these microcracks harmless to ensure the safety and reliability of offshore structures. Here, the dependence of the aspect ratio (As) of the maximum depth of harmless crack $\left(a_{h l m}\right)$ was evaluated under three different conditions considering the threshold stress intensity factor $\left(\Delta K_{t h}\right)$ and residual stress of offshore structural steel F690. The threshold stress intensity factor and fatigue limit of fatigue crack propagation, dependent on crack dimensions, were evaluated using Ando's equation, which considers the plastic behavior of fatigue and the stress ratio. $a_{h l m}$ by peening was analyzed using the relationship between $\Delta K_{\text {th }}$ obtained by Ando's equation and $\Delta K_{\text {th }}$ obtained by the sum of applied stress and residual stress. The plate specimen had a width $2 \mathrm{~W}=12 \mathrm{~mm}$ and thickness $t=20 \mathrm{~mm}$, and four value of As were considered: 1.0, 0.6, 0.3, and 0.1. The $a_{h l m}$ was larger as the compressive residual stress distribution increased. Additionally, an increase in the values of As and $\Delta K_{t h(l)}$ led to a larger $a_{h l m}$. With a safety factor $(N)$ of 2.0, the long-term safety and reliability of structures constructed using F690 can be secured with needle peening. It is necessary to apply a more sensitive non-destructive inspection technique as a non-destructive inspection method for crack detection could not be used to observe fatigue cracks that reduced the fatigue limit of smooth specimens by 50\% in the three types of residual stresses considered. The usefulness of non-destructive inspection and non-damaging techniques was reviewed based on the relationship between $a_{h l m}, a_{N D I}$ (minimum crack depth detectable in non-destructive inspection), $a_{c r N}$ (crack depth that reduces the fatigue limit to $1 / N$ ), and As.

\section{Introduction}

Offshore construction generally refers to the installation of structures and facilities in the marine environment for the production and transportation of electricity, petroleum, gas, and other resources. The shipbuilding industry is growing globally owing to the increasing freight volume, and drilling rigs are also actively being constructed for the development of marine resources (Lee et al., 2011; Song et al., 2013; Kim and Kim, 2018). High-strength steels are used to construct these offshore structures as they are becoming increasingly large and the environments in which they are used are becoming increasingly harsh. However, the possibility of microcracks developing in high-strength steels is high in harsh environments (variable load action), and cracks that have formed can grow rapidly. Microcracks can develop when processing materials and when transporting and installing these structures. To ensure the safety and reliability of offshore structures, initial defects that lead to microcracking should be rendered harmless.

Recently, many researchers have been actively attempting to render cracks harmless using peening. Peening effectively induces a compressive residual stress in high-strength steel (Al-Hassani, 1982; Al-Obaid, 1990; Harada et al., 2007) and increases its fatigue life and strength (Lee and Kim, 1997; Benedetti et al., 2002). As the heat-affected zone of welds is prone to cracking, studies have been conducted on improving fatigue life and rendering cracks harmless by peening the weld toe (Houjou et al., 2013a; Fueki et al., 2015; Fueki et al., 2019). Furthermore, studies simulating the behavior of steels with existing microcracks have been conducted to investigate the use of peening to render cracks harmless (Takahashi et al., 2012; Houjou et al., 2013b). A crack is determined to be harmless using the relationship

Received 11 May 2021, revised 21 June 2021, accepted 9 July 2021

Corresponding author Ki-Woo Nam: +82-51-629-6358, namkw@pknu.ac.kr

(C) 2021, The Korean Society of Ocean Engineers

This is an open access article distributed under the terms of the creative commons attribution non-commercial license (http://creativecommons.org/licenses/by-nc/4.0) which permits unrestricted non-commercial use, distribution, and reproduction in any medium, provided the original work is properly cited 
between the stress intensity factor and the crack size based on the acting stress and compressive residual stress (Nakagawa et al., 2014; Ando et al., 2021; Nam et al., 2021). Each stress intensity factor is evaluated using the Newman-Raju equation (Newman and Raju, 1981) and API-RP579's equation (American Petroleum Institute, API, 2000). Equations to determine the threshold stress intensity factor of a microcrack have been proposed by El Haddad et al. (1979), Tange et al. (1991), and Ando et al. (2019). In particular, Ando et al. proposed an evaluation equation that depends on the crack size, considering the peculiar plastic behavior and stress ratio of fatigue in high-strength steels. This equation can be used to evaluate the fatigue limit and the threshold stress intensity factor of microcracks in high-strength steels (Ando et al., 2020; Ando et al., 2021; Park et al., 2020; Park et al., 2021; Kim et al., 2020).

This study aimed to evaluate the dependence of the maximum depth of a harmless crack $\left(a_{h l m}\right)$ in needle peening (NP)-applied offshore structural steel F690 on the compressive residual stress distribution, threshold stress intensity factor range for large cracks $\left(\Delta K_{t h(l)}\right)$, and crack aspect ratio $(A s)$. Furthermore, we evaluated the maximum allowable crack depth at an assumed safety factor $(N)\left(a_{c r N}\right)$, the minimum detectable crack depth via nondestructive inspection and $a_{h l m}\left(a_{N D I}\right)$, and the crack aspect dependence of $a_{h l m}$.

\section{Materials and Experimental Methods}

\subsection{Materials and Model Specimens}

This study investigated high-strength steel DNV F690, which is used in offshore structures. Table 1 describes the chemical composition of DNV F690 and Table 2 lists its mechanical properties. As shown in Fig. 1, the model specimen has a plate width $2 W=12 \mathrm{~mm}$ and a thickness $t=20 \mathrm{~mm}$; a four-point bending fatigue stress with a

Table 1 Chemical compositions of DNV F690 (wt.\%)

\begin{tabular}{lllllllllllll}
$\mathrm{C}$ & $\mathrm{Si}$ & $\mathrm{Mn}$ & $\mathrm{P}$ & $\mathrm{S}$ & $\mathrm{Cr}$ & $\mathrm{Ni}$ & $\mathrm{Mo}$ & $\mathrm{Al}$ & $\mathrm{Cu}$ & $\mathrm{Nb}$ & $\mathrm{V}$ & $\mathrm{Ti}$ \\
\hline
\end{tabular}

$\begin{array}{lllllllllllll}0.18 & 0.46 & 1.6 & 0.025 & 0.025 & 0.18 & 0.36 & 0.05 & 0.045 & 0.28 & 0.038 & 0.03 & 0.02\end{array}$

Table 2 Mechanical properties of DNV F690

\begin{tabular}{ccc}
\hline Yield strength (MPa) & Tensile strength (MPa) & Elongation (\%) \\
\hline 851 & 876 & 15.2 \\
\hline
\end{tabular}

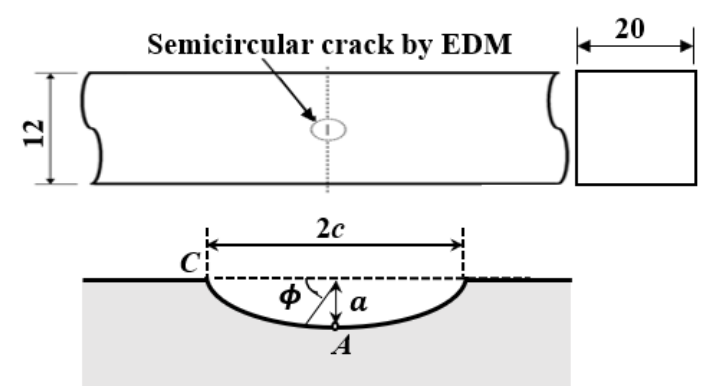

Fig. 1 Schematic of a finite plate containing a semicircular crack stress ratio $R=0.1$ is applied, as in a previous study (Kim et al., 2021). A semicircular crack with a surface crack length $(2 c)$ and depth $(a)$ exists at the center of the specimen. We assumed four crack aspect ratios $(A s=a / c): 1.0,0.6,0.3$, and 0.1 .

\subsection{Residual Stress Distribution}

Three types of compressive residual stress (1), (2), and (3) induced by $\mathrm{NP}$ were assumed in order to evaluate their effect on $a_{h l m}$, as shown in Fig. 2. Residual stress (2) was obtained in an experiment (Kim et al., 2021). Residual stress (1) was the surface compressive residual stress of residual stress (2) $+100 \mathrm{MPa}$, and residual stress (3) was the surface compressive residual stress of residual stress (2) - $150 \mathrm{MPa}$. In the figure, $\sigma_{s}$ is the compressive residual stress of the surface, $\sigma_{\max }$ is the maximum compressive residual stress, $d_{\max }$ is the depth at which the maximum compressive residual stress is observed, and $d_{0}$ is the point where the compressive residual stress is 0 . Table 3 summarizes these values. The fatigue limit of the smooth specimen was $740 \mathrm{MPa}$ and that of the NP smooth specimen was $750 \mathrm{MPa}$ (Kim et al., 2021). $\Delta K_{t h(l)}$ of the smooth specimen obtained experimentally was 6.5 $\mathrm{MPa} \sqrt{\mathrm{m}}$, but we assumed three values $(3,5$, and $7 \mathrm{MPa} \sqrt{\mathrm{m}})$ to evaluate the effect of $\Delta K_{t h(l)}$. In general, $\Delta K_{t h(l)}$ is related to the hardness of a material, and as the hardness increases, $\Delta K_{t h(l)}$ decreases. In this study, considering that the hardness of $\mathrm{F} 690$ varies depending on the heat treatment applied, we selected the three values of $\Delta K_{t h(l)}$. The fatigue limit of the NP smooth specimen depends on the residual stress distribution and $\Delta K_{t h(l)}$, but we assumed that the fatigue limit of the NP smooth specimens was identical to evaluate the dependence of $a_{h l m}$ on the residual stress distribution and $\Delta K_{t h(l)}$.

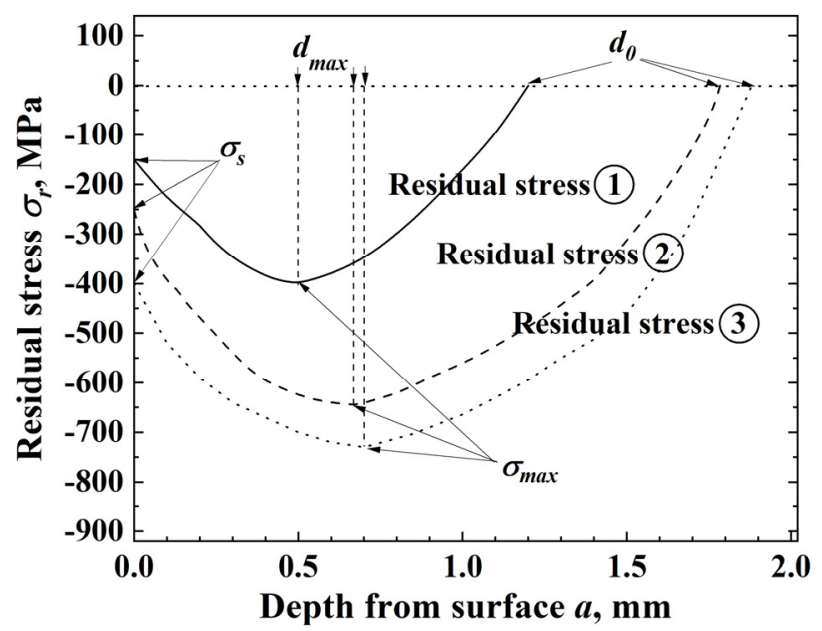

Fig. 2 Three types of residual stresses considered in this study

Table 3 Parameters of considered residual stresses

\begin{tabular}{ccccc}
\hline & $\sigma_{s}(\mathrm{MPa})$ & $\sigma_{\max }(\mathrm{MPa})$ & $d_{\max }(\mathrm{mm})$ & $d_{0}(\mathrm{~mm})$ \\
\hline RS1 & -150 & -400 & 0.5 & 1.2 \\
RS2 & -250 & -647 & 0.676 & 1.784 \\
RS3 & -400 & -731 & 0.697 & 2.150 \\
\hline
\end{tabular}




\subsection{Evaluation Method}

In this study, we used Eq. (1), which was originally proposed by Ando et al. (Ando et al., 2019). This equation describes the dependence of the threshold stress intensity factor range $\left(\Delta K_{t h}\right)$ on crack length when an existing crack in an infinite plate propagates under fatigue stress.

$$
\begin{aligned}
& \Delta K_{t h}=2 \beta \Delta \sigma_{w} \sqrt{\frac{a}{\pi}} \cos ^{-1}\left\{\frac{\pi}{8 \beta^{2} a}\left(\frac{\Delta K_{t h(l)}}{\Delta \sigma_{w}}\right)^{2}+1\right\}^{-1} \\
& \beta=\frac{H\left(\frac{a}{t}, \frac{a}{c}, \frac{c}{b}, \phi\right) F\left(\frac{a}{t}, \frac{a}{c}, \frac{c}{b}, \phi\right)}{\sqrt{Q\left(\frac{a}{c}\right)}}
\end{aligned}
$$

where $a$ is the crack length, $\Delta K_{t h(l)}$ is the threshold stress intensity factor range for large cracks, $\Delta \sigma_{w}$ is the fatigue limit of the non-peened smooth specimen, $\beta$ is a function of $\phi$ in Fig. 1 and a shape factor obtained by the Newman-Raju equation (Newman and Raju, 1981). In contrast, the fatigue limit of the cracked specimen $\left(\Delta \sigma_{w c}\right)$ can be evaluated using Eq. (2).

$$
\triangle K_{t h}=\triangle \sigma_{w c} \sqrt{\pi a}
$$

Eqs. (1)-(2) are used to determine $\Delta K_{t h}$ and $\Delta \sigma_{w c}$ for the deepest part of the crack (point A) in the cracked specimen to which bending stress is applied. To determine these values on the outermost surface (point C), $a$ can be replaced with $c$ in Eqs. (1) and (2).

We evaluated the crack depths corresponding to fatigue limit reduction rates of $25 \%$ and $50 \%$ in the smooth specimens. These crack depths are denoted by $a_{25}$ and $a_{50}$. In our evaluation, the safety factor $(S F)$ for the fatigue limit was set to 2.0, as suggested in the standard established by the American Society of Mechanical Engineers (ASME). As $a_{25}$ decreases till SF reaches 1.5 , these cracks can always be detected via nondestructive inspection. Furthermore, in the case of $S F=2.0$, the maximum crack depth that can exist after a certain period is $a_{50}$. Therefore, if there are no internal defects, surface crack nondamaging technology can ensure the safety of the cracks of $a_{50}$ by peening.

$$
\begin{aligned}
& a_{25} \text { and } a_{50} \text { were evaluated using Eq. (3): } \\
& \Delta K_{a p}=\Delta K_{t h(s)}
\end{aligned}
$$

where $\Delta K_{a p}$ is the stress intensity factor based on bending stress; it can be calculated using the Newman-Raju equation (Newman and Raju, 1981). In other words, $\Delta K_{a p}$ is a stress intensity factor obtained by considering a $25 \%$ and $50 \%$ lower stress than the fatigue limit of the smooth specimen. In this case, $\Delta K_{a p}$ was evaluated at points $\mathrm{A}$ and $\mathrm{C}$ in Fig. 1, and a small crack size was used.

In contrast, the stress intensity factor of the NP specimen was evaluated using Eq. (4):

$$
\Delta K_{T r}=\Delta K_{a p}+K_{r}
$$

where the stress intensity factor $K_{r}$ based on the compressive residual stress was calculated using a stress intensity factor evaluation equation for surface cracks, considering the stress distribution shown in a four-order polynomial provided by API-RP579 (API, 2000). The stress intensity factor of a semi-circular crack existing in a plate is represented by Eq. (5):

$$
\begin{aligned}
K_{r} & =\left[G_{0} \sigma_{0}+G_{1} \sigma_{1}\left(\frac{a}{t}\right)+G_{2} \sigma_{2}\left(\frac{a}{t}\right)^{2}+G_{3} \sigma_{3}\left(\frac{a}{t}\right)^{3}+G_{4} \sigma_{4}\left(\frac{a}{t}\right)^{4}\right] \sqrt{\frac{\pi a}{Q}} f_{w} \\
Q & =1.0+1.464\left(\frac{a}{c}\right)^{1.65} \\
f_{w} & =\left\{\sec \left(\frac{\pi c}{2 W} \sqrt{\frac{a}{t}}\right)\right\}^{0.5}
\end{aligned}
$$

where $G_{0}-G_{4}$ are the shape correction factors of the stress intensity factor determined by API-RP579. $a$ and $c$ represent the depth and surface length of the semi-circular crack, respectively. $W$ and $t$ are the width and thickness of the plate, respectively. $\sigma_{0}-\sigma_{4}$ are the factors obtained from the fourth-order polynomial approximation of the residual stress distribution.

$$
\sigma(x)=\sigma_{0}+\sigma_{1}\left(\frac{x}{t}\right)+\sigma_{2}\left(\frac{x}{t}\right)^{2}+\sigma_{3}\left(\frac{x}{t}\right)^{3}+\sigma_{4}\left(\frac{x}{t}\right)^{4}
$$

where $x$ is the distance along the depth direction from the surface to the crack. In this study, the fourth-order polynomial approximation was used for the three types of compressive residual stress distributions shown in Fig. 2 to evaluate $K_{r}$. Table 4 lists the factors $\sigma_{0}$ $-\sigma_{4}$ obtained from the fourth-order polynomial approximation of residual stress distribution.

Table 4 Factors obtained from fourth-order polynomial of residual stress distribution

\begin{tabular}{cccccc}
\hline & $\sigma_{4}$ & $\sigma_{3}$ & $\sigma_{2}$ & $\sigma_{1}$ & $\sigma_{0}$ \\
\hline RS1 & $-8.46 \mathrm{E}+07$ & $8.56 \mathrm{E}+06$ & $1.03 \mathrm{E}+05$ & $-1.64 \mathrm{E}+04$ & $-1.48 \mathrm{E}+02$ \\
RS2 & $-1.75 \mathrm{E}+07$ & $-8.74 \mathrm{E}+05$ & $4.82 \mathrm{E}+05$ & $-2.56 \mathrm{E}+04$ & $-2.69 \mathrm{E}+02$ \\
RS3 & $2.89 \mathrm{E}+07$ & $-6.04 \mathrm{E}+06$ & $5.98 \mathrm{E}+05$ & $-2.36 \mathrm{E}+04$ & $-4.05 \mathrm{E}+02$ \\
\hline
\end{tabular}

Eq. (7) expresses the determining condition of $a_{h l m}$ of the NP specimen:

$$
\Delta K_{T r}=\Delta K_{t h(s)}
$$

Eq. (7) was reviewed at points A and C, in Fig. 1, and a small crack size was determined with $a_{h l m}$.

The detection probability of a semi-circular fatigue crack was studied by Rummel et al. (1974). They reported that the ultrasonic 
detection method showed the best detection probability of fatigue cracks. According to them, cracks with a $100 \%$ detection probability in the optimal conditions of the laboratory using this method had $2 c=12$ $\mathrm{mm}$ and $a=4 \mathrm{~mm}$. Moreover, cracks with a $50 \%$ detection probability had $2 c=1.2 \mathrm{~mm}$ and $a=0.26 \mathrm{~mm}$. The minimum crack dimensions were $c=a=0.17 \mathrm{~mm}$. Recently, other researchers detected stress corrosion cracking with a depth (a) of $0.4 \mathrm{~mm}$ (Ochiai et al., 2006); however, since they did not mention the length, it was assumed to be a semi-circular crack. In this study, based on the above literature, we assumed that the ultrasonic detection method can sufficiently detect a semi-circular crack of $2 c=0.6 \mathrm{~mm}$ and $a=0.3 \mathrm{~mm}$. Among ultrasonic testing methods, the echo reflection method's echo intensity depends on the crack area. The area $(S)$ of a semi-circular crack can be represented by Eq. (8):

$$
S=\pi a c / 2
$$

In other words, if the area of a semi-circular crack $(S)$ is the same, even if the crack aspect ratio ( $A s)$ changes, the crack detection probability remains the same. Therefore, if the area of a semi-circular crack of $2 c=0.6 \mathrm{~mm}$ and $a=0.3 \mathrm{~mm}$ is $S_{N D I}$, then the relationship between the maximum crack size $a_{N D I}$ that can be detected from $S_{N D I}$ and $A s$ can be expressed by Eq. (9):

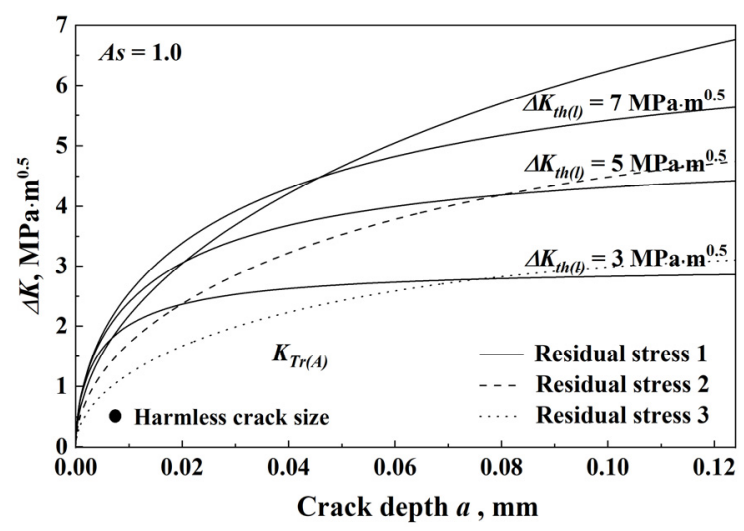

(a)

$$
S_{N D I}=\pi a_{N D I}^{2} / 2 A s
$$

\section{Results and Discussion}

Fig. 3 shows the crack depth ( $a$ ) dependence of $\Delta K_{t h}$ and $\Delta K_{T r}$ for residual stresses (1), (2), and (3) in the case of $A s=1.0$. Fig. 3(a) shows the results at point A, and Fig. 3(b) shows the results at point C. Eq. (7) expresses the condition for determining the maximum harmless crack dimensions using NP, and the small crack dimensions of point $\mathrm{A}$ and point $\mathrm{C}$ are selected. These crack dimensions are marked with $\mathbf{O}$. In the case of $A s=1.0, a_{h l m}$ values of residual stresses (1), (2), and (3) were determined at point $\mathrm{C}$ for all $\Delta K_{t h(l)}$.

Fig. 4 shows the crack depth ( $a$ ) dependence of $\Delta K_{t h}$ and $\Delta K_{T r}$ for residual stresses (1), (2), and (3) in the case of $A s=0.6$. Fig. 4(a) shows the results at point A, and Fig. 4(b) shows the results at point C. In this case also, the crack dimensions that determine the maximum harmless crack dimensions are marked with . In the case of $A s=0.6, a_{h l m}$ of residual stress (1) was determined at point A for all $\Delta K_{t h(l)}$. While $a_{h l m}$ of residual stress (2) was determined at point $\mathrm{A}$ in the cases of $\Delta K_{t h(l)}$ $=3 \mathrm{MPa} \sqrt{\mathrm{m}}$ and $\Delta K_{t h(l)}=5 \mathrm{MPa} \sqrt{\mathrm{m}}$, it was determined at point $\mathrm{C}$ in the case of. In contrast, of residual stress (3) was determined at point A in the case of $\Delta K_{t h(l)}=3 \mathrm{MPa} \sqrt{\mathrm{m}}$ and at point $\mathrm{C}$ in the cases of

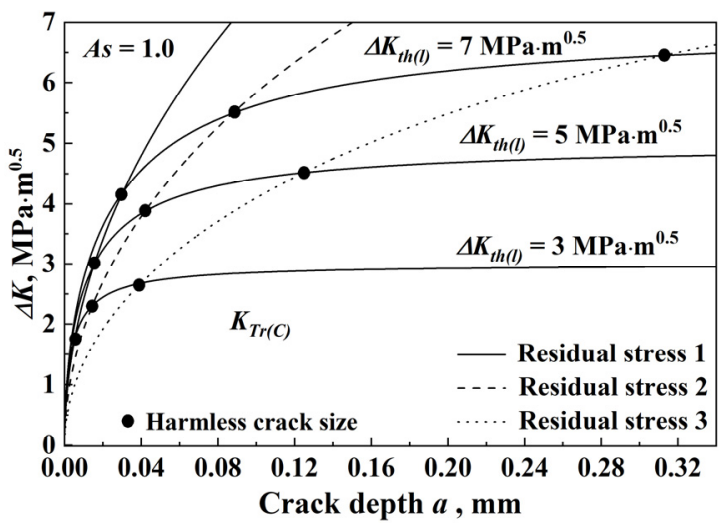

(b)

Fig. 3 Crack depth dependence of $\Delta K_{t h}$ and $\Delta K_{T r}$ at (a) point $\mathrm{A}$ and (b) point $\mathrm{C}$ in the case of $A s=1.0$

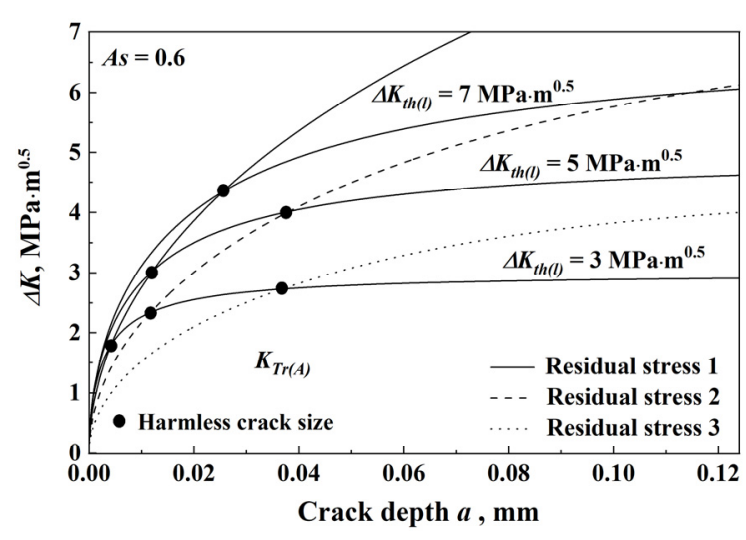

(a)

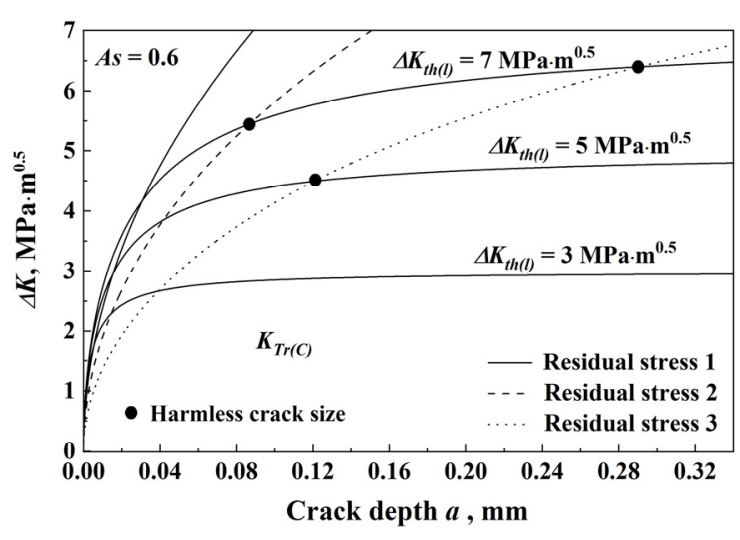

(b)

Fig. 4 Crack depth dependence of $\Delta K_{t h}$ and $\Delta K_{T r}$ at (a) point $\mathrm{A}$ and (b) point $\mathrm{C}$ in the case of $A s=0.6$ 


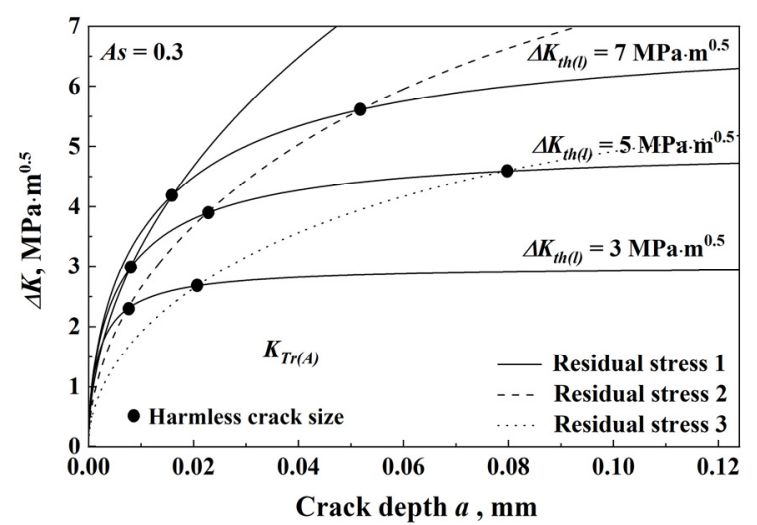

(a)

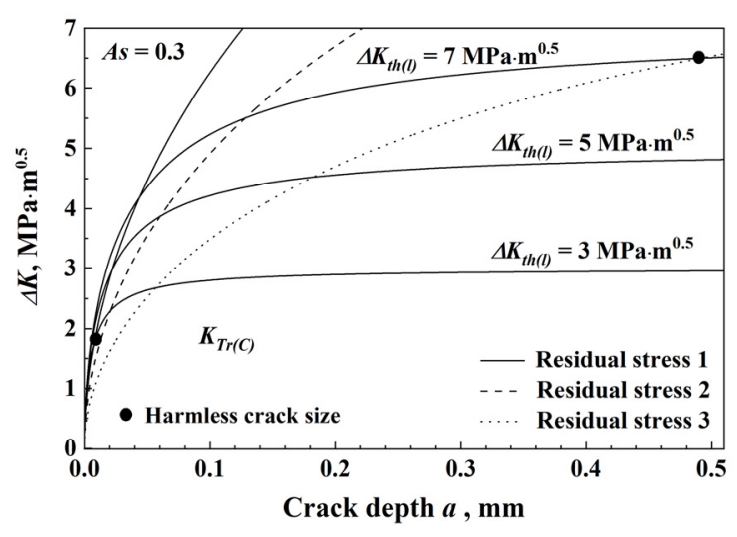

(b)

Fig. 5 Crack depth dependence of $\Delta K_{t h}$ and $\Delta K_{T r}$ at (a) point $\mathrm{A}$ and (b) point $\mathrm{C}$ in the case of $A s=0.3$

$\Delta K_{t h(l)}=5 \mathrm{MPa} \sqrt{\mathrm{m}}$ and $\Delta K_{t h(l)}=7 \mathrm{MPa} \sqrt{\mathrm{m}}$.

Fig. 5 shows the crack depth (a) dependence of $\Delta K_{t h}$ and $\Delta K_{T r}$ in the case of $A s=0.3$ for residual stresses (1), (2), and (3). Fig. 5(a) shows the results at point A, Fig. 5(b) shows the results at point C. In this case also, the crack dimensions that determine the maximum harmless crack dimensions are marked with 0 . In the case of $A s=$ 0.3 , of residual stress (1) was determined at point $\mathrm{A}$ when $\Delta K_{t h(l)}=5$ $\mathrm{MPa} \sqrt{\mathrm{m}}$ and $\Delta K_{t h(l)}=7 \mathrm{MPa} \sqrt{\mathrm{m}}$, but it was determined at point $\mathrm{C}$ when $\Delta K_{t h(l)}=3 \mathrm{MPa} \sqrt{\mathrm{m}} \cdot a_{h l m}$ of residual stress (2) was determined at point A for all $\Delta K_{t h(l)}$. In contrast, $a_{h l m}$ of residual stress (3) was determined at point $\mathrm{A}$ when $\Delta K_{t h(l)}=3 \mathrm{MPa} \sqrt{\mathrm{m}}$ and $\Delta K_{t h(l)}=5$ $\mathrm{MPa} \sqrt{\mathrm{m}}$ and at point $\mathrm{C}$ when $\Delta K_{t h(l)}=7 \mathrm{MPa} \sqrt{\mathrm{m}}$.

Fig. 6 shows the crack depth ( $a$ ) dependence of $\Delta K_{t h}$ and $\Delta K_{T r}$ in the case of $A s=0.1$ for residual stresses (1), (2), and (3). Fig. 6(a) shows the results at point $\mathrm{A}$, and Fig. 6(b) shows the results at point $\mathrm{C}$. In this case also, the crack dimensions that determine the maximum harmless crack dimensions are marked with 0. In the case of $A s=0.1$, $a_{h l m}$ values of residual stresses (1) and (2) were determined at point $\mathrm{A}$ for all $\Delta K_{t h(l)}$. However, $a_{h l m}$ of residual stress (3) was determined at point $\mathrm{A}$ in the cases of $\Delta K_{t h(l)}=3 \mathrm{MPa} \sqrt{\mathrm{m}}$ and $\Delta K_{t h(l)}=5 \mathrm{MPa} \sqrt{\mathrm{m}}$ and at point $\mathrm{C}$ in the case of $\Delta K_{t h(l)}=7 \mathrm{MPa} \sqrt{\mathrm{m}}$.

The surface crack nondamaging technology using NP is employed

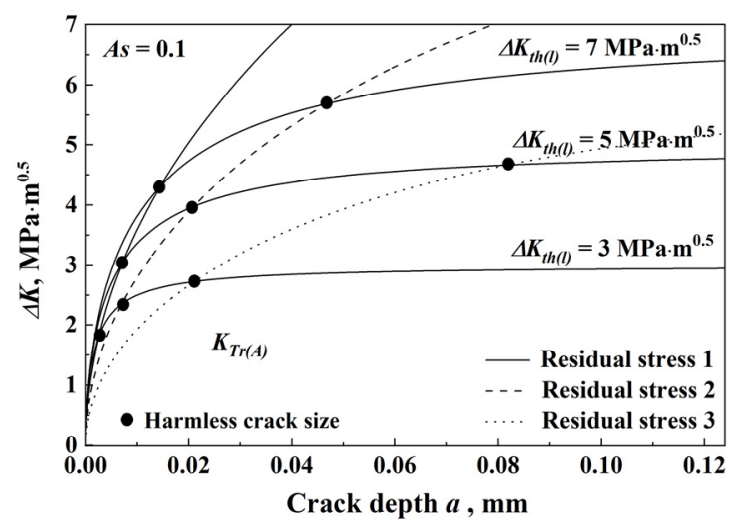

(a) to ensure safety of structures. Fig. 7 shows the crack aspect ratio dependence of $a_{h l m}$ when using NP. In Figs. 7(a), 7(b), and 7(c), $\Delta K_{t h(l)}$ values are 3,5 , and $7 \mathrm{MPa} \sqrt{\mathrm{m}}$, respectively. $a_{h l m}$ was larger when the residual stress distribution was larger and deeper, indicating that $a_{h l m}$ was considerably affected by the residual stress distribution. Furthermore, $A s$ and $\Delta K_{t h(l)}$ increased, $a_{h l m}$ increased.

Fig. 7 shows the crack depths corresponding to fatigue limit reduction rates of $25 \%$ and $50 \%\left(a_{25}, a_{50}\right)$ in the non-NP specimens. The crack depth showed a decreasing tendency $A s$ decreased. Furthermore, the figure shows the relationship between $a_{N D I}$ and $A s$, which was evaluated using Eq. (9).

In Fig. 7(a), since $a_{h l m}$ of residual stress (1) is below $a_{50}$, it cannot be rendered harmless. Since $a_{h l m}$ of residual stress (2) is below $a_{50}$, it can not be rendered harmless; however, since it is above $a_{25}$, it can be rendered harmless. Meanwhile, since $a_{h l m}$ of residual stress (3) is above $a_{50}$, it can be rendered harmless. Based on this, residual stress (3) can ensure the safety of structures that use this material via the surface crack nondamaging technology. In contrast, the crack detection ability ) determined by the above-assumed non-destructive inspection is above $a_{50}$. Therefore, it is difficult to detect cracks of $a_{50}$ by using this non-destructive inspection, and it is necessary to apply a more sensitive non-destructive inspection technique.

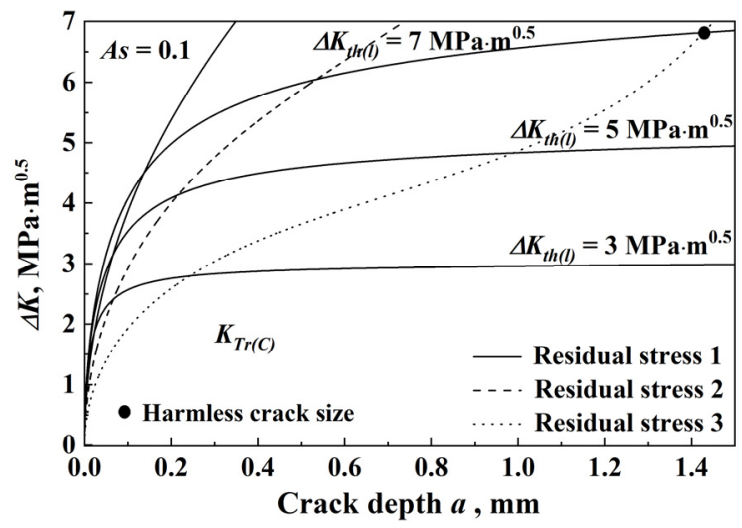

(b)

Fig. 6 Crack depth dependence of $\Delta K_{t h}$ and $\Delta K_{T r}$ at (a) point $\mathrm{A}$ and (b) point $\mathrm{C}$ in the case of $A s=0.1$. 


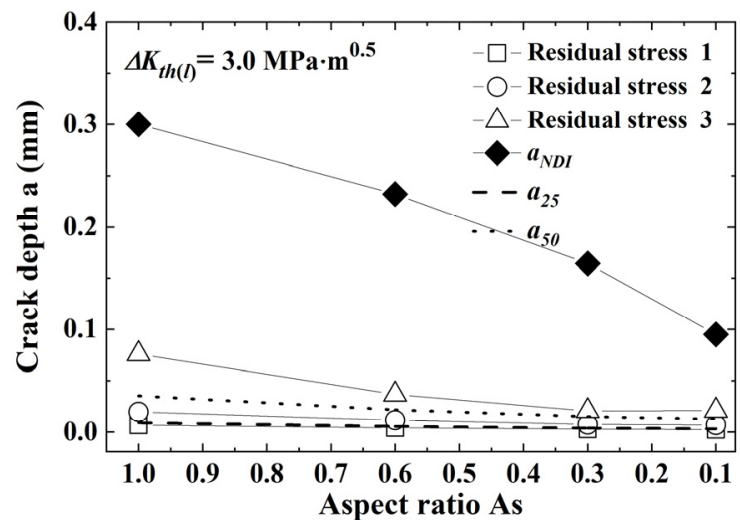

(a) $\Delta K_{t h(l)}=3.0 \mathrm{MPa} \sqrt{\mathrm{m}}$

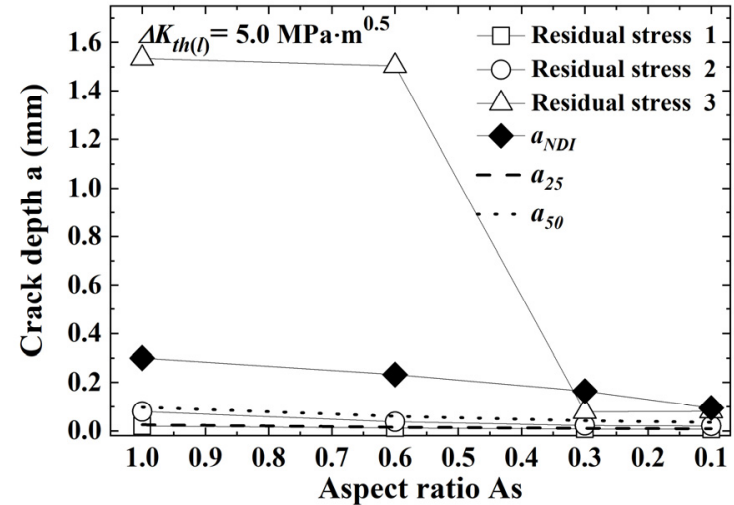

(b) $\Delta K_{t h(l)}=5.0 \mathrm{MPa} \sqrt{\mathrm{m}}$

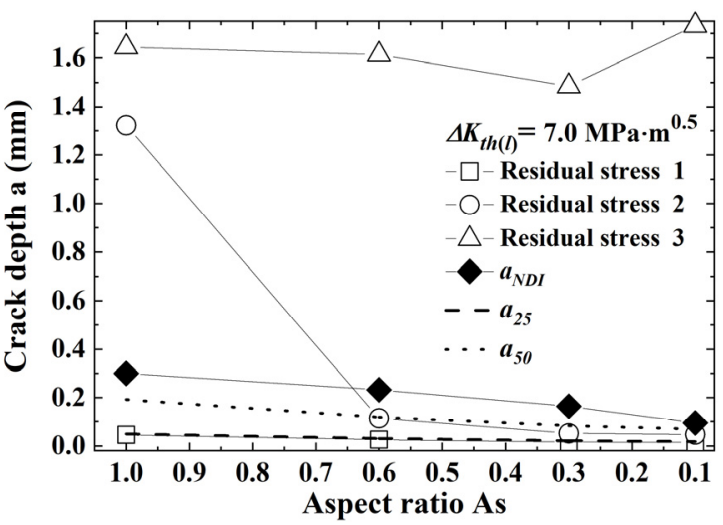

(c) $\Delta K_{t h(l)}=7.0 \mathrm{MPa} \sqrt{\mathrm{m}}$

Fig. 7 Effect of $A s$ on the rendered harmless crack depth $\left(a_{h l m}\right), a_{25}$ and $a_{50}$

In Fig. 7(b), since $a_{h l m}$ of residual stress (1) is below $a_{25}$, it can not be rendered harmless. Since $a_{h l m}$ of residual stress (2) is above $a_{25}$, it can be rendered harmless. However, since it is below $a_{50}$, it cannot be rendered harmless. $a_{h l m}$ of residual stress (3) can be rendered harmless since it is above $a_{50}$. Based on this, residual stress (3), determined using the surface crack nondamaging technology, can ensure the safety of structures that use this material. In contrast, the crack detection ability ( $\diamond$ ) determined by the above-assumed non-destructive inspection is above $a_{50}$. Therefore, it is difficult to detect cracks of $a_{50}$ by using this non-destructive inspection, and it is necessary to apply a more sensitive non-destructive inspection technique.

In Fig. 7(c), since $a_{h l m}$ of residual stress (1) is below $a_{25}$, it cannot be rendered harmless. Furthermore, since $a_{h l m}$ of residual stress (2) is above $a_{25}$, it can be rendered harmless; however, since it is below $a_{50}$ except for $a_{h l m}$ of $A s=1.0$, it cannot be rendered harmless. $a_{h l m}$ of residual stress (3) can be rendered harmless since it is above $a_{50}$. Based on this, residual stress (3) can ensure the safety of structures that use this material via the surface crack nondamaging technology. In contrast, the crack detection ability $(\diamond)$ determined by the above-assumed non-destructive inspection is above $a_{50}$. Therefore, it is difficult to detect cracks of $a_{50}$ by using this non-destructive inspection, and it is necessary to apply a more sensitive non-destructive inspection technique.
Based on this, residual stress (1), determined by the surface crack nondamaging technology, cannot ensure the safety of structures that use this material; however, residual stress (2) with $A s=1.0$ and residual stress (3) can ensure the safety of structures. In contrast, since the crack detection ability $(\checkmark)$ determined by the non-destructive inspection assumed for residual stresses (2) and (3) is above $a_{50}$, this non-destructive inspection cannot detect cracks of $a_{50}$.

In Fig. 8, examination results of the maintenance and reliability of fatigue failure using non-destructive inspection and surface crack nondamaging technology (Nam et al., 2021) are shown. The schematic diagrams in Figs. 8(a)-8(d) show $a_{h l m}$ and $a_{N D I}$ determined when using NP and the relationship between the crack depth $\left(a_{c r N}\right)$, which reduces the fatigue limit to $1 / \mathrm{N}$, and the crack aspect ratio $(A s)$ when the safety factor is $N$. In Fig. 8(a), the condition is $a_{c r N}<a_{h l m}<a_{N D I}$. Under this condition, the surface crack nondamaging technology can facilitate appropriate maintenance, but the non-destructive inspection cannot facilitate appropriate maintenance. In Fig. 8(b), the condition is $a_{N D I}<a_{c r N}<a_{h l m}$. Under this condition, both non-destructive inspection and the surface crack nondamaging technology can facilitate appropriate maintenance. If NP is performed after non-destructive inspection to ensure complete safety, it can contribute greatly to the shortening of the periodic inspection period because it is required to detect only cracks that are deeper than the crack depth 


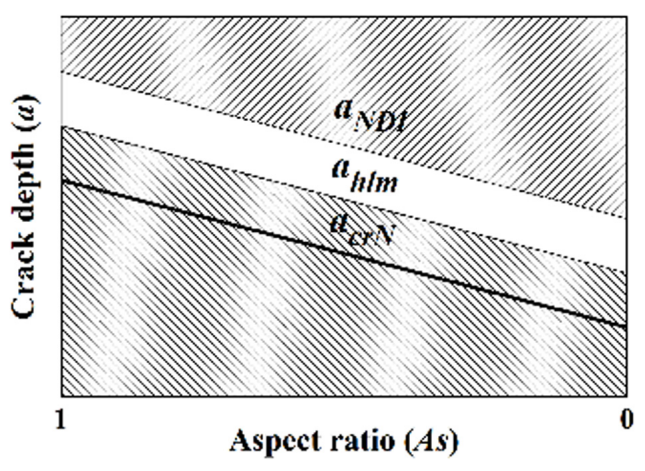

(a) $a_{c r N}<a_{h l m}<a_{N D I}$

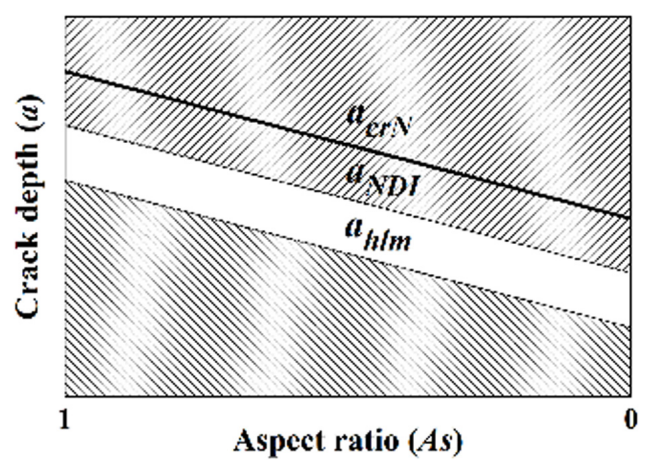

(c) $a_{h l m}<a_{N D I}<a_{c r N}$

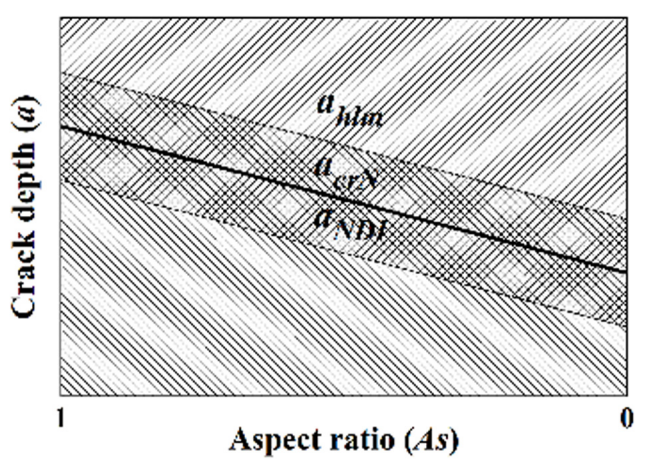

(b) $a_{N D I}<a_{c r N}<a_{h l m}$

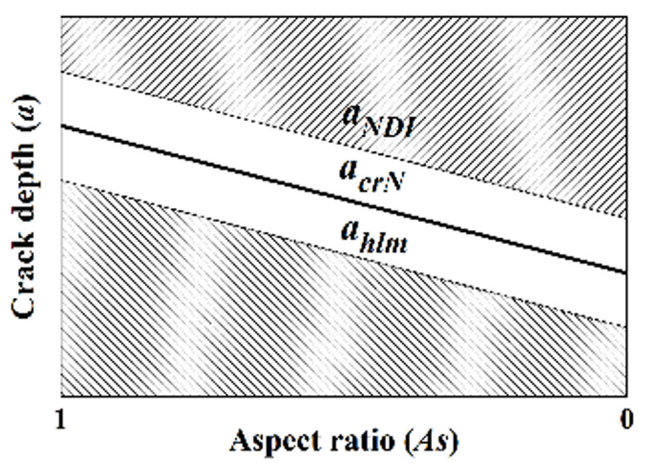

(d) $a_{h l m}<a_{c r N}<a_{N D I}$

Fig. 8 Schematic diagram of the application of surface crack nondamaging techniques and nondestructive inspection to material integrity

corresponding to $a_{h l m}$. In Fig. 8(c), the condition is $a_{h l m}<a_{N D I}<a_{c r N}$. Under this condition, non-destructive inspection alone can facilitate appropriate maintenance, and the surface crack nondamaging technology cannot facilitate appropriate maintenance. In Fig. 8(d), the condition is $a_{h l m}<a_{c r N}<a_{N D I}$. Under this condition, since $a_{c r N}$ is very small, it pertains to structural ceramics, and appropriate maintenance is impossible with non-destructive inspection and the surface crack nondamaging technology. However, peening forms significant residual stress in structural ceramics. Quality assurance can be provided for cracks caused by peening after self-healing.

\section{Conclusion}

In the case of varying $\Delta K_{t h(l)}$ and three types of residual stresses of offshore structural high-strength steel F690, we evaluated As dependence of $\Delta K_{t h(l)}$ and $A s$ dependence of crack depths $\left(a_{25}\right.$ and $\left.a_{50}\right)$ corresponding to fatigue limit reduction rates of $25 \%$ and $50 \%$ in Non-NP specimens. Furthermore, in the case where the fatigue crack surface is the same irrespective of $A s$, we evaluated the As dependence of $a_{N D I}$ using high-performance non-destructive inspection. Based on the results, we examined how the surface crack nondamaging technology will contribute to the longevity of F690 and the reliability of maintenance. The conclusions drawn are as follows.

(1) $a_{h l m}$ was larger when the residual stress distribution was larger and deeper, indicating that $a_{h l m}$ was considerably affected by the residual stress distribution. Furthermore, as $A s$ and $\Delta K_{t h(l)}$ increased, $a_{h l m}$ increased.

(2) At $\Delta K_{t h(l)}=3,5$, and $7 \mathrm{MPa} \sqrt{\mathrm{m}}, a_{h l m}$ of residual stress (3) is above $a_{50}$, and at $\Delta K_{t h(l)}=7 \mathrm{MPa} \sqrt{\mathrm{m}}$ in the case of residual stress (2), $a_{h l m}$ of $A s=1.0$ is above $a_{50}$. Therefore, in the case of $N=2.0$, the safety and reliability of F690 used for a long time can be ensured when using NP.

(3) Since the crack detection ability $(\checkmark)$ determined by the assumed non-destructive inspection cannot detect $a_{50}$ at residual stresses (1), (2), and (3), it is necessary to apply a more sensitive non-destructive inspection technique.

(4) With the relationship of $a_{h l m}, a_{N D I}$, and $a_{c r N}$ with $A s$, we examined the usefulness of non-destructive inspection and the crack nondamaging technology.

\section{Funding}

This work was supported by a Research Grant of Pukyong National University (2021).

\section{References}

Al-Hassani, S.T.S. (1982). The Shot Peening of Metals - Mechanics and Structures. SAE Transactions, 91(4), 4513-4525. Retrieved July 27, 2021, from http://www.jstor.org/stable/44634444

Al-Obaid, Y.F. (1990). A Rudimentary Analysis of Improving Fatigue Life of Metals by Shot-Peening. Journal of Applied Mechanics, 
57(2), 307-312. https://doi.org/10.1115/1.2891990

Ando, K., Fueki, R., Nam, K.W., Matsui, K., \& Takahashi, K. (2019).

A Study on the Unification of the Threshold Stress Itensity Factor for Micro Crack Growth. Transactions of Japan Society for Spring Engineers, 2019(64), 39-44. https://doi.org/10.5346/ trbane.2019.39

Ando, K., Nam, K.W., Kim, M.H., Ishii, T., \& Takahashi, K. (2020). Analysis of Peculiar Fatigue Fracture Behavior of Shot Peened Steels Focusing on Threshold Stress Intensity Factor Range. Transactions of Japan Society for Spring Engineers, 2020(65), 35 -41. https://doi.org/10.5346/trbane.2020.35

Ando, K., Kim, M.H., \& Nam, K.W. (2021). Analysis on Peculiar Fatigue Fracture Behavior of Shot Peened Metal Using New Threshold Stress Intensity Range Equation. Fatigue \& Fracture of Engineering Materials \& Structures, 44(2), 306-316. https://doi.org/10.1111/ffe.13356

American Petroleum Institute (API). (2000). Recommended Practice 579, Fitness for Service. American Petroleum Institute, C3-C10.

Benedetti, M., Fontanari, V., Höhn, B.R., Oster, P., \& Tobie, T. (2002). Influence of Shot Peening on Bending Tooth Fatigue Limit of Case Hardened Gears. International Journal of Fatigue, 24(11), 1127-1136. https://doi.org/10.1016/S0142-1123(02) 00034-8

EI Haddad, M.H., Topper, T.H., \& Smith, K.N. (1979). Prediction of non Propagating Cracks. Engineering Fracture Mechanics, 11(3), 573-584. https://doi.org/10.1016/0013-7944(79)90081-X

Fueki, R., Takahashi, K., \& Houjou. K. (2015). Fatigue Limit Prediction and Estimation for the Crack Size Rendered Harmless by Peening for Welded Joint Containing a Surface Crack. Materials Sciences and Applications, 6(6), 500-510. https://doi.org/10.4236/msa.2015.66053

Fueki, R., Takahashi, K., \& Handa, M. (2019). Fatigue Limit Improvement and Rendering Defects Harmless by Needle Peening for High Tensile Steel Welded Joint. Metals, 9(2), 143, https://doi.org/10.3390/met9020143

Harada, Y., Fukaura, K., \& Haga, S. (2007). Influence of Microshot Peening on Surface Layer Characteristics of Structural Steel. Journal of Materials Processing Technology, 191(1-3), 297-301. https://doi.org/10.1016/j.jmatprotec.2007.03.026

Houjou, K., Takahashi, K., Ando, K., \& Sekiguchi, Y. (2013a). Improvement of Fatigue Limit and Rendering Crack Harmless by Peening for Rolled Steel Containing a Crack at the Weld Toe Zone. Transactions of the Japan Society of Mechanical Engineers A, 79(797), 110-114. https://doi.org/10.1299/kikaia.79.110

Houjou, K., Takahashi, K., \& Ando, K. (2013b). Improvement of Fatigue Limit by Shot Peening for High-Tensile Strength Steel Containing a Crack in the Stress Concentration Zone. International Journal of Structural Integrity, 4(2), 258-266. https://doi.org/10.1108/17579861311321726

Kim, J.H., \& Kim, Y.I. (2018). Numerical Simulation on the Response of Moored Semi-submersible Under Ice Load. Journal of Ocean
Engineering and Technology, 32(3), 177-183. https://doi.org/ 10.26748/KSOE.2018.6.32.3.177

Kim, M.H., Hyun, J.Y., \& Nam, K.W. (2020). Evaluation of Harmless Crack Size using Ando's Equation. Journal of Mechanical Science and Technology, 34, 1971-1977. https://doi.org/ 10.1007/s12206-020-0418-7

Kim, M.H., Lee, W.G., Kim, C.S., Takahashi, K., Handa, M., \& Nam, K.W. (2021). Evaluation of Fatigue Limit and Harmless Crack Size of Needle Peened Offshore Structure Steel F690. Journal of Mechanical Science and Technology, 35(9), 3855-3862. https://doi.org/10.1007/s12206-021-2109-4

Lee, J.G., \& Kim, J.K. (1997). Influence of Residual Stress Due to Shot Peening on Fatigue Strength and Life. Transactions of the Korean Society of Mechanical Engineers A, 21(9), 1498-1506. https://doi.org/10.22634/KSME-A.1997.21.9.1498

Lee, K.Y., Choi, H.S., Lee, E.J., \& Yoon, T.S. (2011). Future Vision Through NL Tensioner Technology Development and Domestic Equipment Fabrication. Journal of Ocean Engineering and Technology, 25(2), 127-133. https://doi.org/10.5574/KSOE. 2011.25.2.127

Nakagawa, M., Takahashi, K., Osada, T., Okada, H., \& Koike, H. (2014). Improvement in Fatigue Limit by Shot Peening for High-Strength Steel Containing Crack-like Surface Defect (Influence of Surface Crack Aspect Ratio). Japan Society of Spring Engineers, 2014(59), 13-18. https://doi.org/10.5346/ trbane. 2014.13

Nam, K.W., Ando, K., Kim, M.H., \& Takahashi, K. (2021). Improving Reliability of High Strength Steel Designed Against Fatigue Limit using Surface Crack Nondamaging Technology by Shot Peening. Fatigue \& Fracture of Engineering Materials \& Structures, 44(6), 1062-1610. https://doi.org/10.1111/ffe.13460

Newman, J.C.Jr., \& Raju, I.S. (1981). An Empirical Stress-Intensity Factor Equation for the Surface Crack. Engineering Fracture Mechanics, 15(1-2), 185-192. https://doi.org/10.1016/00137944(81)90116-8

Ochiai, M., Miura, T., \& Yamamoto, S. (2006). Laser-Ultrasonic Nondestructive Testing and Its Application to Nuclear Industry. Toshiba Review, 61(1), 44-47.

Park, H.S., Kim, M.H., \& Nam, K.W. (2020). A Study on the Threshold Stress Intensity Factor and Fatigue Limit of Short Crack Growth. Transactions of the Korean Society of Mechanical Engineers A, 44(11), 781-786. https://doi.org/10.3795/KSME-A. 2020.44.11.781

Park, H.S., Kim, M.H., \& Nam, K.W. (2021). Study of Threshold Stress Intensity Factor and Fatigue Limit for Through Crack in Infinite Plate and Semi-Elliptical Surface Crack in Finite Plate. Transactions of the Korean Society of Mechanical Engineers A, 45(2), 133-139. https://doi.org/10.3795/KSME-A.2021.45.2.133

Rummel, W.D., Todd, P.H. Jr., Frecska, S.A., \& Rathke, R.A. (1974). The Detection of Fatigue Cracks by Nondestructive Testing Methods (Report NASA-CR-2369). NASA Contractor. 
Song, C.Y., Choi, H.Y., \& Shim, S.H. (2013). Structural Safety Evaluation of Marine Loading Arm Using Finite Element Analysis. JJournal of Ocean Engineering and Technology, 27(1), 43-50. https://doi.org/10.5574/KSOE.2013.27.1.043

Takahashi, K., Okada, H., \& Ando, K. (2012). Effects of Shot Peening on the Torsional Fatigue Limit of High-Strength Steel Containing an Artificial Surface Defect. International Journal of Structural Integrity, 3(3), 274-284. https://doi.org/10.1108/175798612 11264389

Tange, A., Akutu, T., \& Takamura, N. (1991). Relation Between Shot-Peening Residual Stress Distribution and Fatigue Crack
Propagation Life in Spring Steel. Transactions of Japan Society for Spring Engineers, 1991(36), 47-53. https://doi.org/10. 5346/trbane.1991.47

\section{Author ORCIDs}

Author name

Lee, Weon-Gu

ORCID

Gu, Kyoung-Hee

0000-0002-3098-4018

$0000-0001-5364-4713$

$0000-0002-8057-8771$

0000-0001-7019-358X 